\title{
LAS HOSPEDERÍAS EN EL LITORAL DEL REINO DE GRANADA: LOS MESONES DE MOTRIL EN EL CATASTRO DE ENSENADA
}

\author{
RaÚl Ruiz Álvarez* \\ UNIVERSIDAD DE GRANADA \\ Centro de Estudios Históricos del Valle de Lecrín y La Alpujarra
}

\begin{abstract}
RESUMEN
En este trabajo hemos realizado un mapa de las hospederías del litoral del reino de Granada, desde Estepona hasta Vera, partiendo de los datos que nos aporta el Catastro del marqués de la Ensenada. Históricamente, el comercio por el litoral se ha realizado por mar, lo que no significa que no existiese una red de caminos y veredas, si bien este aspecto no ha recibido especial atención hasta el momento. Esta investigación no solo nos ha permitido recabar datos de interés sobre la localización y la propiedad de estos servicios para comprender su papel en el conjunto del reino de Granada, sino que además, hemos estudiado pormenorizadamente los mesones de Motril, indagando en las actas capitulares del Concejo o en la documentación del Archivo Histórico de la Nobleza, entre otros, cuestiones sobre su estructura, el capital fiscal de sus propietarios, la legislación local o las personas que ejercían el oficio de mesoneros y sus familias.
\end{abstract}

PALABRAS CLAVE: hospederías, litoral del reino de Granada, Motril, caminos, Catastro de Ensenada

*raul.lanjaron@gmail.com 


\title{
THE HOSTELRIES IN THE LITORAL OF THE KINGDOM OF GRANADA: MOTRIL INNS IN THE "CATASTRO DE ENSENADA"
}

\author{
RaÚl Ruiz ÁlVAREz* \\ UnIVERSIDAD DE GRANADA \\ Centro de Estudios Históricos del Valle de Lecrín y La Alpujarra
}

\begin{abstract}
In this paper, we present a detailed map of hostelreis of the Kingdom of Granada during the 18th century. This map includes inns from Estopona to Vera and it has been elaborated with the documentation of the "Catastro del marqués de la Ensenada". Historically, in the coastline of the Kingdom of Granada, the main commercial routes were maritime. However, there were also non-described alternative inland commercial routes composed of a network of roads and paths that are studied in this paper. This research shows relevant data of the main location and ownership of the hostelries. These data are employed to explain the crucial role of the inland commercial routes in the Kingdom of Granada. More specifically, a meticulous description of hosteleries in Motril was conducted by collecting the information of the Chapter Acts or the documents of Historical Archive of the Nobility, among others. In this case, references to the building structure, tax information and/or details of the everyday life of the innkeepers are included.
\end{abstract}

KEYWORDS: hostelries, Kingdom of Granada coastline, Motril, paths and roads, "Catastro de Ensenada"

*raul.lanjaron@gmail.com 


\section{INTRODUCCIÓN}

Las hospederías prestaban un servicio básico en la Edad Moderna para el descanso de las gentes y animales que transitaban los caminos, villas y ciudades de la Península. De entre todas ellas, destacaban las ventas en los caminos y despoblados y los mesones en los núcleos urbanos, lo que nos suscitará algunas preguntas relacionadas con el número de estas infraestructuras, su ubicación, su propiedad, su explotación, e incluso con los problemas que surgen en torno a estos espacios y que se verán reflejados en las normativas estatales y locales, advirtiéndose a lo largo de la Edad Moderna un aumento del interés por la mejora del servicio, la seguridad y la propia infraestructura, sin olvidar los gravámenes que se les cobraban por la venta de determinados productos.

Este trabajo es parte de una investigación más amplia que estamos desarrollando sobre las hospederías en el reino de Granada ${ }^{1}$. El objetivo de este estudio es analizar a partir de los datos que nos aporta el Catastro del marqués de la Ensenada, la propiedad de estos establecimientos de hospedaje, su estructura edilicia, y su explotación. Para ello nos detendremos en la pregunta veintinueve del interrogatorio de las Respuestas Generales que muestra una información estandarizada, lo que nos permitirá hacer comparaciones e indagar en los datos que aporta el vecindario, especialmente en la búsqueda de los propietarios y mesoneros, para ver el perfil de sus hogares. Además, los libros de los Cabezas de Casa y de lo Real -tanto de eclesiásticos como de seglares-, nos ofrecen datos muy útiles para conocer el capital fiscal de propietarios, mesoneros o instituciones en el litoral.

En la investigación realizada sobre las hospederías en el reino de Granada ya señalamos la poca presencia de hospederías en el litoral, a

1. Actualmente se encuentran en prensa dos artículos sobre: "Ventas, Mesones y Posadas en el reino de Granada (s. XVIII)" en el que se realiza un primer balance historiográfico y a partir de los datos que nos aporta el Catastro del marqués de la Ensenada y otras fuentes documentales y literarias sobre las edificaciones de hospedaje del reino de Granada en el siglo XVIII, se presenta un estudio sobre la terminología, la legislación, la localización, la propiedad o la explotación; y "Ventas y Mesones en el Valle de Lecrín, Órgiva, Torvizcón y las Alpujarras (s. XVIII)" en el que se estudia pormenorizadamente su localización, profundizando en las que se ubican en los caminos que van de Granada a Almuñécar, a Motril y a Ugíjar; se trazan los perfiles socioeconómicos de sus propietarios; se indaga sobre quienes las explotaban; y por último se documentan algunas de sus características edilicias y se analiza su presencia en el paisaje rural o urbano a través de imágenes y datos proporcionados por diferentes fuentes. 
excepción de la ciudad de Málaga que contaba con dieciséis mesones, tres hosterías y dos ventorrillos; Estepona con cinco posadas; Vélez-Málaga con tres mesones; y tanto Almería como Motril con cuatro. Esta circunstancia ha motivado que dediquemos el primer epígrafe a estudiar las hospederías en el litoral, trazando un mapa que nos permita saber su cifra y disposición desde Estepona a Vera. Para ello, hemos realizado un croquis con los caminos y veredas que unirían los municipios de la costa, siempre condicionados a la orografía de un territorio esculpido entre ramblas, acantilados y barrancos, entre calas y playas. Un territorio que contaba con las ventajas del comercio marítimo, tanto de largo alcance, como de cabotaje que ponía en contacto localidades cercanas, y con las consecuencias de una red viaria entre municipios costeros muy deficiente. La existencia de un medio físico caracterizado por una dificultosa orografía, claramente condicionó la debilidad de las vías de comunicación y del comercio terrestre, que a su vez debió influir en la localización y número de las infraestructuras de hospedaje del litoral.

En otro apartado nos centramos en estudiar los mesones de la ciudad de Motril, que, situada entre Málaga y Almería, tenía un puerto que empezaba a destacar por el comercio de azúcar y otros víveres, aunque su desarrollo estará condicionado por la piratería y por el desarrollo que experimenta el puerto malagueño en esta centuria. Motril no estaba conectada con camino de ruedas a la capital del Reino, sino por un camino de herradura que subiría hasta la venta de la Cebada para discurrir por el Valle de Lecrín atravesando Pinos del Valle y Restábal hasta llegar a la venta de Padul y tomar el camino a Granada, en el que podríamos hacer una parada en el ventorrillo de Otura o el mesón de Alhendín, antes de adentrarnos en la capital, que contaba en 1752 con veintiséis mesones.

Así pues, nos vamos a circunscribir cronológicamente al siglo XVIII y geográficamente a la costa del reino de Granada, deteniéndonos en los mesones de Motril a partir de los datos que nos aporta el Catastro de Ensenada, y para su análisis, también utilizaremos la documentación de las actas capitulares de Motril y del Archivo Histórico de la Nobleza.

\section{LAS HOSPEDERÍAS EN EL LITORAL DEL REINO DE GRANADA}

A partir de las Respuestas Generales hemos podido documentar doscientos setenta y dos servicios de hospedería distribuidos en las trescientas noventa y nueve localidades del reino de Granada. Se concentraban en las principales ciudades, núcleos de comercio y caminos de tránsito, 
pero también los encontramos diseminados en pequeñas villas y caminos secundarios.

Las reformas borbónicas del siglo XVIII se ocuparon de los caminos y por ende de estos servicios. El gran proyecto de caminería para diseñar un sistema radial con centro en Madrid se publicó en un Real Decreto el 10 de junio de 1761. Pero, como señala la historiografía, en lo que respecta al reino de Granada, en esta centuria todo quedaría en unas pocas obras de importancia como la construcción de la carretera de Málaga a Antequera ${ }^{2}$.

No obstante, el litoral tiene sus propios condicionantes en lo que se refiere a las comunicaciones terrestres. Así, encontramos diferencias tangenciales entre unas localidades y otras, lo que determinaría el tráfico de personas, animales, objetos, ideas o mercancías. La costa del reino de Granada es un territorio muy extenso en el que podemos situar un centro de importancia que sería Málaga, cuyo peso económico, demográfico, social y comercial también se traslada al número de hospederías. En el siglo XVIII el puerto de Málaga se convertirá en un punto estratégico del Mediterráneo.

Partiendo desde Estepona hacia Almería por Marbella, Málaga, VélezMálaga, Almuñécar, Salobreña y Motril, habría un paso terrestre en paralelo al litoral mediterráneo que comunicaría estas localidades. No tenemos noticias de que este eje costero fuese una ruta importante ni para el comercio, ni para el tránsito de viajeros, sino más bien, todo lo contrario. La circulación, debido a la orografía, sería muy precaria por veredas en las que incluso el camino con bestias sería en algunos tramos casi imposible. Santos Madrazo se refiere a estos caminos costeros como insoportables, peligrosos y con falta de puentes $^{3}$. Pese a que se mejoraron algo, debido en mayor parte al interés del abasto de pan y otros productos, lo cierto es que las mejoras de caminos se centrarían más en las comunicaciones con el interior. Jurado Sánchez habla de un litoral sin caminos hasta el siglo XIX debido al relieve, el clima, y la piratería, fundamentalmente de bereberes ${ }^{4}$. Estos vacíos de comunicación se plasman en los repertorios oficiales y estatales condicionando la economía de la zona. No obstante, las vías de comunicación por el litoral encuentran excepciones como el tramo entre Málaga y Vélez-Málaga, que en el siglo XVIII llegaría a ser un camino de ruedas o el tramo entre Motril y Calahonda, que sería necesario para el tráfico de mercancías entre el varadero del puerto y la ciudad.

2. J. JuRAdo SÁnchez (1992), 73-106.

3. S. Madrazo Madrazo (1984), 303.

4. J. Jurado SÁnchez (1988), 34-35. 
Por el contrario, las localidades costeras cuentan con el transporte de productos por mar mediante el sistema denominado de cabotaje que unía territorios no muy distantes entre sí. Por tanto, contando con un sistema de comercio marítimo entre las localidades de la costa, el interés se centraría en mejorar las comunicaciones hacia el interior para poder mantener un comercio fluido ${ }^{5}$. Los caminos que unían las principales localidades costeras con el interior irían adquiriendo mayor importancia a lo largo del siglo, sobre todo en el caso de Málaga. Destacan los caminos de:

a) Málaga a Osuna, a Antequera, y a Granada por Vélez-Málaga y Alhama de Granada, lo que explica la importancia del comercio marítimo malagueño y la evolución de caminos de herradura a caminos de ruedas. Por ejemplo, la carretera a Antequera se finalizaría en 1789 y se acometerían obras en la de Málaga-Granada por Vélez-Málaga ${ }^{6}$ y Alhama de Granada con el objetivo de ensancharla hasta los 10 metros para que se pudiera circular. Además se construirían puentes sobre el arroyo del Judío y sobre Jaral, o se arreglarían los de los ríos Vélez y Rubite ${ }^{7}$.

b) De Almuñécar a Granada ${ }^{8}$. El carril de Almuñécar fue especialmente promocionado por los Reyes Católicos para conectar Granada con el puerto en aquella ciudad y aunque en el XVIII parece muy decadente continuó en uso como demuestra la presencia de hospederías o tráfico arriero.

c) De Motril a Granada9 . La Junta de Caminos de Granada no se ocupó especialmente de este camino, a excepción de algunos arreglos en su tramo entre Granada y Padul, por lo que continuó siendo un camino de herradura durante todo el siglo.

d) De Almería a Guadix ${ }^{10}$. Encontramos una red viaria abandonada, que sería casi la única vía de comunicación entre Almería y Granada, pues la alternativa era un entramado de comunicaciones por la costa que constituía una carrera de obstáculos físicos y también humanos, con continuos ataques bereberes, que dificultaban el tránsito.

5. M. Diago Hernando y M. Á. Ladero Quesada (2009), 347-382.

6. A. Burgos Núñez, J. C. Olmo García y M. P. Sáez Pérez (2015), 36-63; P. Pezzi Cristóbal (2003), 212-229; J. Brotons Pazos (1995).

7. J. JuRAdo SÁnchez (1988), 74-75.

8. Sobre el carril de Almuñécar, véase M. M. Birriel SAlcedo (1989); A. Jiménez Estrella y J. C. Maroto Martos (2004).

9. J. JuRAdo SÁnchez (1988), 81-82.

10. Ibidem, 87. 
Como ya hemos mencionado, en el conjunto del litoral localizamos diferencias substanciales, aunque podemos afirmar que conforme caminamos hacia el este el estado de los caminos costeros empeora, así como los índices económicos y demográficos de las localidades. Este hecho se ve reflejado directamente en la densidad de hospederías, pues la cercanía a polos comerciales como el puerto de Málaga o incluso al propio Motril influye en su número y localización, corroborando que las hospederías están ligadas a los caminos, pero como hemos aclarado en otros trabajos, no necesariamente en los caminos principales, y en la costa se ve claramente en los ejemplos del mesón de Albuñol, Ojén, Arenas del Rey, o Benamocarra. También podemos aseverar la casi inexistencia de ventas en los caminos de litoral andaluz. Llama la atención que, a excepción de los dos ventorrillos que había a las afueras de Málaga, ubicados en el camino que iba a Vélez-Málaga, no hemos documentado esta infraestructura en el camino litoral, siendo todas las hospederías de carácter urbano. Seguramente la falta de ventas en los caminos sea consecuencia del poco desarrollo de las vías de comunicación terrestres por el litoral. Por un lado tenemos una red de comunicaciones muy precaria que une las localidades de la costa y que no recibiría gran interés en el siglo XVIII, por el poco tránsito; y por otro, una red que une los principales puertos con el interior, que sería muy desigual, que estaría vinculada principalmente al comercio y en la que se producen cambios sustanciales en la segunda mitad del siglo.

Para poder comprobar la densidad de estas infraestructuras en el territorio hemos elaborado un croquis a partir del mapa geográfico que Tomás López realizó en 1795, en el que se ha trazado la vía costera superponiendo una línea sobre el camino que dibuja el geógrafo, e indicado los mesones, posadas, hosterías, ventas y ventorrillos que aparecen en el litoral del Reino. Es decir, a partir del mapa referido y los datos de las Respuestas Generales del Catastro del marqués de la Ensenada, en la primera imagen se destacan los caminos y veredas de la costa del Reino, y en la segunda imagen se extrae el trazado de esos caminos y veredas y sobre el mismo se sitúan las ventas, ventorrillos, hosterías y mesones localizados tanto en dicho camino, como en otros municipios cercanos, lo que nos brinda una aproximación a la densidad de estas infraestructuras y su localización en el camino o en los núcleos urbanos. En resumen, hemos trabajado superponiendo este croquis a dicho mapa para poder situar las localidades y los servicios de hospedería urbanos, y para poder trazar la línea de los caminos estudiados, y también comprender la orografía del terreno, pues Tomás López detalla en este documento el relieve por montes de perfil y sombreado, el arbolado, 
las poblaciones, y las divisiones administrativas, siendo un excelente mapa para poder situar las hospederías que hemos documentado.

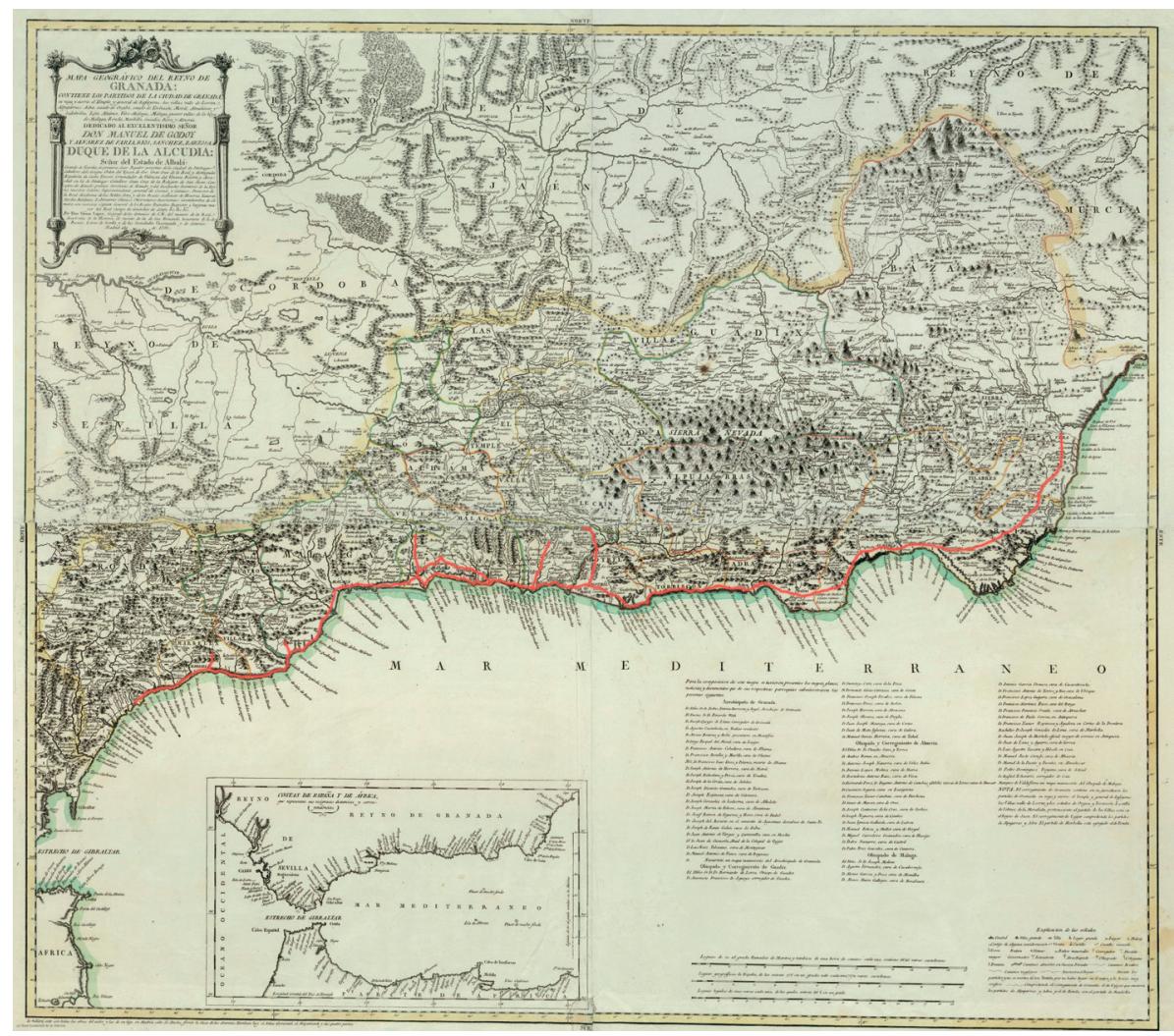

Imagen 1. Trazado de los caminos del litoral del reino de Granada sobre el Mapa geográfico del Reyno de Granada (1795) de Tomás López ${ }^{11}$.

11. T. LóPez, Mapa geográfico del Reyno de Granada (1795). Biblioteca Nacional. MR/2/82 digma1dig. URL: http://bdh-rd.bne.es/viewer.vm?id=0000033456. "Mapa geográfico del Reyno de Granada: Contiene los Partidos de la Ciudad de Granada, su vega y sierra, el Témple y general de Zafayona, las villas, Valle de Lecrin, Alpujarras, Adra, estado de Orgiba, estado de Torbiscon, Motril, Almuñécar y Salobreña, Lója, Alhama, VelezMálaga, quatro villas de la hoya de Malaga, Ronda, Marbélla, Guadix, Báza y Almería. Escala [ca. 1:400.000]. 15 Leguas de 20 al grado, llamadas de Marina y tambien de una hora de camino cada una contiene 6626 varas castellanas $[=20,2 \mathrm{~cm}]$ ”. 
Las hospederías en el litoral del reino de Granada: los mesones de Motril... 259

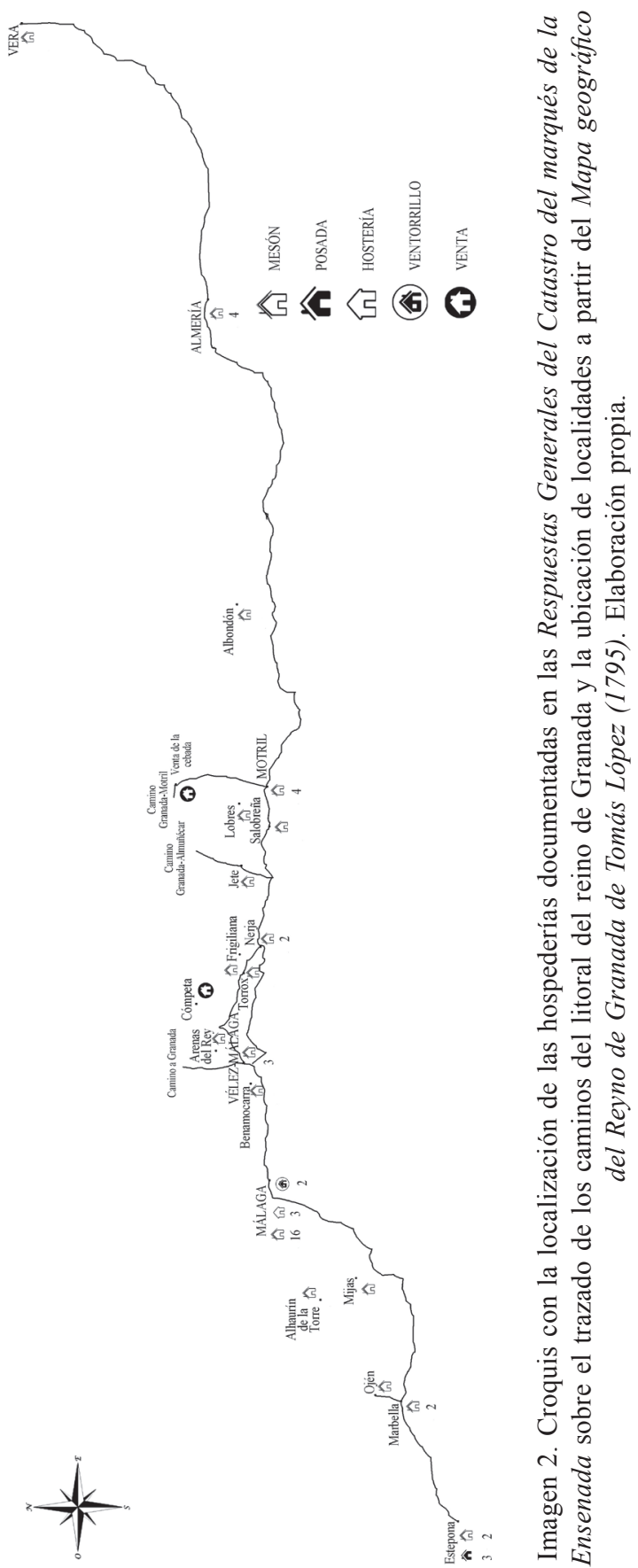

(C) Baetica. Estudios Historia Moderna y Contemporánea, 39, 2019, 251-283. Facultad de Filosofia y Letras, Universidad de Málaga. Departamento de Historia Moderna y Contemporánea 
Comenzando por la villa de Estepona ${ }^{12}$, encontramos en su núcleo urbano cinco hospederías. De estas cinco, dos son mesones, uno (al que se le regula una utilidad de 100 ducados) es propiedad a medias de la capellanía que posee don Bartolomé de Caravaca y Valencia y de los herederos de don Benito Serrato; y el otro que dará de utilidad 900 reales de vellón, es propiedad de don Diego Santiago. Las otras tres son posadas; una de María del Río que le da de utilidad 220 reales de vellón; otra de Francisco Galán, que le da 50 reales de vellón y otra de Francisco Barbuena que le da 132 reales de vellón. Estas son las únicas posadas que registra el Catastro de Ensenada en todo el reino de Granada con esta terminología.

Dirigiéndonos hacia oriente por la costa, el siguiente servicio de hospedaje lo localizamos en la ciudad de Marbella ${ }^{13}$, que cuenta con dos mesones, uno en el ruedo de la plaza pública, y otro junto a la Puerta del Mar. Ambos pertenecen al Hospital y buena Memoria que en esta ciudad fundó el capitán Alonso Varan con el título de Santa María de la Encarnación, produciendo anualmente 1.000 reales de vellón, de los que le deja a José Eusebio, cortador de carne y mesonero, una utilidad de 500 reales de vellón por su explotación.

Por el camino trazado en el mapa de Tomás López, no encontramos más infraestructuras de hospedaje hasta llegar a Málaga ${ }^{14}$, con sus 16 mesones, 3 hosterías y 2 ventorrillos. De los cuatro ventorrillos o ventas disminuidas que he documentado en el Reino, dos estaban situados a la salida de la ciudad de Málaga, en el camino real a Vélez-Málaga, uno propiedad de don Alonso Berdugo que le producía 300 reales de vellón y el otro de los herederos de don Juan Cruzado, que le produce otros 300 reales de vellón. No he encontrado ninguna característica que nos haga creer que las hosterías y los mesones son diferentes. En todo caso, es llamativo que el Catastro solo registre tres en el reino de Granada, y las tres en la ciudad de Málaga. La hostería de La Cruz de Oro, está a cargo de Francisco Gras; la hostería La Cruz de Plata está a cargo de Pedro Guiral y la otra está en la Puerta de Espartería propiedad de Juan Cody. Finalmente, el Catastro registra dieciséis mesones, aunque comience diciendo que hay quince (uno de los errores que se cometen al escribir el Catastro): el mesón de la Guadalmedina, que nombran propiedad de

12. Archivo General de Simancas (AGS), Catastro de Ensenada (CE), Respuestas Generales (RG) Estepona, Libro 287, fols. 59v-49v.

13. AGS, CE, RG Marbella, Libro 293, fols. 78v-79r.

14. AGS, CE, RG Málaga, Libro 295, fols. 141v-150r. 
los herederos de Aranda, vecinos de Sevilla, y que ocupa José Ruiz; el mesón Patio propio de la condesa de Donadío, vecina de Jaén, que tiene arrendado Pedro de la Torre; el mesón Victoria propio del convento de Religiosos Victoria de Málaga, que tiene arrendado Juana Vélez; el mesón Calderera propio de los señores deán y cabildo de la santa Iglesia de Málaga, arrendado por Blas Sharín; el mesón Costilla, propio del conde de Casapalma, que tiene en arriendo Ignacio de Mesa; el mesón de Vélez propiedad del marqués de Villadarías y que tiene arrendado Juan de Gálvez; el mesón de Illescas propiedad del convento y monjas del Cister de ella, cuyo arrendatario es Ambrosio Martínez; el mesón de la calle de la Armona, propio del colegio de la Compañía de Jesús, que lo sirve de mesonero Pedro de Otero; otro mesón de don Juan de Molina Martel arrendado por Pedro Sánchez; el mesón del Confitero de don Antonio Vezayas que tiene en arriendo Fernando Arévalo; el mesón Rosario cuya propiedad tiene la capilla de Nuestra Señora del Rosario, situada en el convento de reverendos padres dominicos de la ciudad de Málaga, y que está arrendado a Francisco González; el mesón Cruz, propio de don Francisco Velázquez y arrendado a Juan Gómez Carnero; el mesón del barrio de la Trinidad propiedad de la Santa Iglesia Catedral que tiene en arriendo Juan Manuel; el mesón Cucharro, propio de los herederos de don Jorge Boeto, arrendado a Francisco de la Peña; el mesón de la Tuerta, propio de don Francisco Díez Cruzat, presbítero, que tiene en arriendo Bernardo García; y por último el mesón inmediato al castillo de San Lorenzo, que es propiedad de don Juan José Witemberg, prebendado de esta iglesia, y que explota en arriendo Andrés López.

Dejamos atrás las hospederías de Málaga, y continuamos nuestro viaje hasta Vélez-Málaga ${ }^{15}$ donde había tres mesones: el mesón de don Francisco de Vivar, regidor de esta ciudad, que tiene arrendado Manuel Lastre en 50 ducados; el mesón Estrella propiedad de don José López, que lo tiene arrendado la ciudad en 100 ducados y sirve como cuartel; y el mesón propio de don Francisco Gámez, regidor de esta ciudad y de la marquesa de Valdecañas, vecina de Madrid, que tienen en arriendo a Pedro Ruiz por 100 ducados.

De Vélez-Málaga a Nerja, Tomás López distingue entre dos caminos paralelos al litoral mediterráneo. En este caso tomaremos el del interior que atraviesa las localidades de Algarrobo, Sayalonga, y Torrox. En este

15. AGS, CE, RG Vélez-Málaga, Libro 303, fols. 110v-111v. 
tramo solo encontramos el mesón de Torrox ${ }^{16}$ propio de la capellanía que posee don Francisco Díaz Cruzat, vecino de Málaga. Está arrendado a Pedro Bruno, su mesonero, por 200 reales de vellón al año, y a éste le regulan de utilidad, por la poca providencia que tiene en el mesón de paja y cebada, otros 200 reales de vellón.

En Nerja ${ }^{17}$ el caminante podría alojarse en dos mesones. El mesón de Alejandro Iglesias que le produce 300 reales de vellón al año y el mesón de Antonio Ruiz, que tiene arrendado Juan Carán y que produce la misma cantidad.

El camino continúa hacia Almuñécar ${ }^{18}$, donde no documentamos ninguna hospedería, pero sí una alhóndiga propia de la ciudad que posiblemente daría servicio de hospedería pues se la nombra como mesón-alhóndiga. Para los estudios sobre mesones hemos preferido solo registrar los que tendrían la utilidad principal de servicio de alojamiento, por lo que no la hemos contabilizado, pues habría que realizar un estudio en profundidad para comprobar su aprovechamiento.

El siguiente mesón en el camino es el de Salobreña ${ }^{19}$, que está a cargo de Juan Fernando, y del que no tenemos más información. Y ya en la cercana ciudad de Motril, contabilizamos cuatro mesones de los que daremos cuenta en el siguiente epígrafe.

De Motril a Almería no encontramos ninguna edificación pública para hospedarse en el camino de la costa. En Almería ${ }^{20}$ anotamos cuatro mesones que están situados contiguamente. Son propios de doña Michaela de Entrena, de doña Ana Galindo y de don Antonio Almón, que lo gobierna por sí mismo, pudiendo resultarles cada año de utilidad 50 ducados. El cuarto es propio de José Vázquez, y solo sirve en invierno por lo que se le regulan 25 ducados de utilidad. A ninguno de sus mesoneros se les regula producto por no haber paso en esta ciudad para parte alguna, y por tanto no concurrir huéspedes.

Finalmente, de Almería ${ }^{21}$ hasta cruzar la frontera hacia Murcia, solo encontramos el mesón de Vera, propio de la ciudad, cuyo arrendatario paga anualmente, junto con la carnicería, 100 ducados.

16. AGS, CE, RG Torrox, Libro 302, fols. 84r-v.

17. AGS, CE, RG Nerja, Libro 298, f. 663r.

18. AGS, CE, RG Almuñécar, Libro 275, f. 44rv.

19. AGS, CE, RG Salobreña, Libro 300, f. 387v.

20. AGS, CE, RG Almería, Libro 275, fols. 113r-114r.

21. AGS, CE, RG Vera, Libro 303, fols. 44r-v. 
Por otro lado, hemos querido señalar once mesones que estaban en localidades cercanas a las ya referidas, algunas de ellas situadas en los caminos hacia el interior, y otras en las numerosas redes viarias locales y comarcales que había. Consideramos que nos aportan un mapa más completo de las hospederías que prestarían servicio en la costa. Así, comenzaremos de Occidente a Oriente con el mesón de Ojén ${ }^{22}$, cuya propiedad es de Catalina López, viuda de Diego Pérez de Ocaña y lo tiene arrendado a Juan de los Santos en 104 reales de vellón y 17 maravedís, considerándole de utilidad a dicho arrendador 30 ducados al año.

Continuamos hasta el mesón de Mijas ${ }^{23}$ que estaba a cargo de Moreno Álvarez, al que le regulaban de utilidad 50 ducados al año. En Alhaurín de la Torre ${ }^{24}$ también registramos un mesón propiedad del conde de Puerto Blanco, que arrienda a un particular por 16 ducados anuales. Además, detalla que no es lugar de paso y que solo suelen concurrir a causa del tráfico de pan algunos arrieros del trigo.

Entre Málaga y Vélez-Málaga, muy cerca del camino de Granada se encuentra la localidad de Benamocarra ${ }^{25}$ en la que los propios de la villa poseen una casa mesón en la que también está la carnicería, y por ambas pueden ganar hasta 80 reales de vellón al año. También en el partido de Vélez-Málaga encontramos el mesón de Arenas del $\mathrm{Rey}^{26}$, que tiene en propiedad el conde de Puertollano y gana de arrendamiento 130 reales de vellón al año; y la venta de Cómpeta ${ }^{27}$ situada en el paraje del arroyo del Acebuchal y camino real que va de la ciudad de Granada a Torrox, Frigiliana y Nerja. Esta venta pertenece a Juan de Espinosa, que hace de ventero, y al no encontrarse en lugar de paso y tener poca capacidad, solo se le regulan de utilidad 12 reales de vellón al año. En Frigiliana ${ }^{28}$ también hemos documentado un mesón propiedad del conde de Frigiliana que tiene arrendado en 100 reales de vellón al año.

En el camino de Granada a Almuñécar se encuentra el lugar de Jete ${ }^{29}$, en el que el Catastro registra un mesón de don Andrés Márquez, al que por arriendo le produce 120 reales de vellón al año.

22. AGS, CE, RG Ojén, Libro 297, fols. 650r-v.

23. AGS, CE, RG Mijas, Libro 296, fol. 147r.

24. AGS, CE, RG Alhaurín de la Torre, Libro 276, fols. $817 \mathrm{v}-818 \mathrm{r}$.

25. AGS, CE, RG Benamocarra, Libro 278, fols. 379r-v.

26. AGS, CE, RG Arenas del Rey, Libro 276, fol. 612v.

27. AGS, CE, RG Cómpeta, Libro 285, fols. 383v-384r.

28. AGS, CE, RG Frigiliana, Libro 287, fol. 238r.

29. AGS, CE, RG Gete, Libro 289, fols. 529v-530r. 
En el partido de Salobreña, además del mesón de Salobreña, encontramos el mesón de Lobres $^{30}$ propio de Antonio Rodríguez Mesqua, que lo tiene arrendado a Juan Martin, y una venta en Güajar Faragüit ${ }^{31}$ en el camino de Granada a Motril llamada venta de la Cebada, que está a cargo de Juan de Montasa ${ }^{32}$.

Finalmente, hemos señalado el mesón de Albuñol $^{33}$, propio del conde de Cifuentes, señor de Torvizcón. Por arrendamiento de 80 reales de vellón está a cargo de Juan Parra, al que no se le regula utilidad por tenerlo subarrendado a Juan de Rosasel.

Como resultado del análisis documental del Catastro de Ensenada hemos podido contabilizar en el reino de Granada 44 hospederías que se encuentran en los caminos y veredas del litoral. Además hemos ampliado esa cifra con 11 hospederías que se encuentran en el entorno de esos caminos, por lo que podemos afirmar a partir de los datos que nos ofrece el Catastro que en la costa habría al menos 55 servicios de hospedaje, lo que supone un 20,4\% de las hospederías del Reino.

En el conjunto del litoral del reino que tendría una extensión de unos 450 kilómetros, la mayor parte de estas infraestructuras se concentran en Málaga con el 38,2 \%, seguida de Estepona con el 9,1 \%, Almería y Motril con el 7,3 \% y de Vélez-Málaga con el 5,5\%, siendo una mayoría las localidades que no cuentan con este tipo de infraestructuras.

En cualquier caso, podemos confirmar que el litoral granadino en el siglo XVIII no posee una red articulada de ventas y mesones, disponiéndose en los principales núcleos comerciales y puertos, desde los que parten mejores caminos al interior peninsular. Por un lado, tenemos lo que podemos llamar la gran ciudad costera, Málaga, en la que se encontraban 21 hospederías y de la que partían numerosos caminos al interior; y por otro, lo que predomina en la mayor parte del litoral son mesones en las villas y ciudades más importantes o con más población como Estepona, Marbella, Motril o Almería, siendo su número mayor en el litoral occidental y perdiendo intensidad conforme nos dirigimos hacia oriente.

30. AGS, CE, RG Lobres, Libro 294, fols. 859r-v.

31. AGS, CE, RG Guájar Faragüit, Libro 288, fol. 393v. Esta venta ha sido estudiada por María Aurora Molina Fajardo en su tesis doctoral, y en un reciente artículo que ha sido aceptado en la revista Chronica Nova y que muy amablemente me ha facilitado.

32. Véase M. A. MOLINA FAJARDO (2012), 820-822 y (2019).

33. AGS, CE, RG Albuñol, Libro 276, fol. 212v. 
En cuanto a las localidades cercanas a la costa, de las once que hemos seleccionado, ninguna tiene más de un mesón y su utilidad es muy baja, entre 80 y 160 reales de vellón, lo que nos indica la poca concurrencia de huéspedes, y la poca importancia de las mismas en las economías locales y comarcales.

La propiedad de las hospederías del litoral está mayoritariamente en manos de los dones con la presencia de miembros de las oligarquías locales y del clero. De 55 infraestructuras, nueve son de la nobleza titulada, once del clero entre las que se encuentran propiedades personales de presbíteros, deanes y capellanes, y propiedades de colegios, conventos o la propia iglesia catedral. El resto son en su mayoría dones (15), vecinos (16), propios de las villas y ciudades (2) o instituciones (2). La vecindad de los propietarios es en su mayoría del lugar donde se ubican los servicios de hospedería, con contadas excepciones como la marquesa de Valdecañas, vecina de Madrid, que posee la mitad del mesón Gigantes de Vélez-Málaga, o don Francisco Díaz Cruzat, vecino de Málaga, cuya capellanía es propietaria del mesón de Torrox.

El modelo se asemeja al del conjunto del reino de Granada. De nuevo, los datos aportados por el Catastro de Ensenada indican que son los grupos más acomodados quienes controlan los servicios de hospedaje. Igual pasa con la explotación de los mismos, generalmente en régimen de arrendamiento a mesoneros que vivirían con sus familias en ellos contribuyendo todos los componentes del hogar a las diferentes labores, aunque el Catastro solo le regule industrial al cabeza de la casa. Por último, también quisiéramos señalar la poca presencia de la propiedad femenina de estas infraestructuras, estando entre el 5-7\%, en una proporción muy similar a la del conjunto del reino de Granada.

Motril reproduce el mismo perfil de propietarios. Con tan solo cuatro mesones, la nobleza, el clero y los dones continúan siendo el grupo social más importante en la tenencia de estos servicios como veremos a continuación.

\section{LOS MESONES DE MOTRIL EN EL CATASTRO DE ENSENADA}

Partiendo de la clasificación que realiza el Archivo General de Simancas en el Portal de Archivos Españoles (PARES) ${ }^{34}$, la ciudad de Motril es la cabeza de su Partido que estaba compuesto por Motril, Gualchos, Pataura y Vélez de Benaudalla. Motril, Gualchos y su anejo Jolúcar eran

34. http://pares.mcu.es/

(C) Baetica. Estudios Historia Moderna y Contemporánea, 39, 2019, 251-283. Facultad de Filosofía y Letras, Universidad de Málaga. Departamento de Historia Moderna y Contemporánea 
de realengo, mientras que Vélez de Benaudalla era de señorío y pertenecía a dicha ciudad de Motril ${ }^{35}$.

La respuesta a la pregunta número tres del Interrogatorio General del Catastro del marqués de la Ensenada nos aporta información sobre su localización:

A la tercera pregunta respondieron que esta ciudad ocupa su término de levante a poniente dos leguas, del norte al sur, más de una legua, y de circunferencia siete leguas, y linda por el sur con la mar, por el norte, término de la villa de Vélez de Benaudalla, señorío de esta dicha ciudad y lugar de Luxar, jurisdicción del estado del Cehel, por poniente con el término de la villa de Salobreña, y lugar de Pataura de esta jurisdicción, y por levante con el término del lugar de Gualchos, y Jolúcar de la jurisdicción de esta ciudad, y con el término de dicho lugar de Luxar, y tiene la figura del margen, y responden ${ }^{36}$.

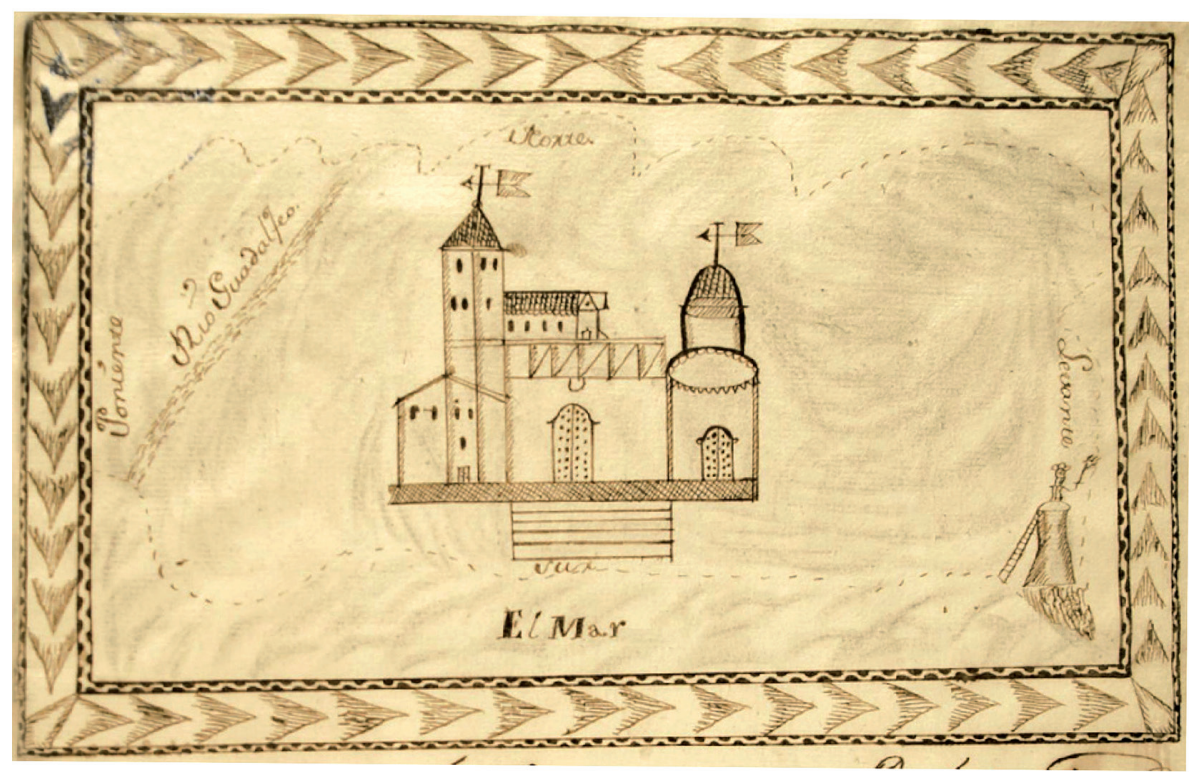

Imagen 3. Croquis de Motril en el Catastro de Ensenada. ${ }^{37}$

35. AGS, CE, RG Gualchos, Libro 289, fol. 347r; AGS, CE, RG Pataura, Libro 298, fol. 458r; AGS, CE, RG Vélez de Benaudalla, Libro 303, fol. 405r.

36. AGS, CE, RG Motril, Libro 293, fols. 700r-v.

37. Imagen de Motril editada por el Archivo Histórico Provincial de Granada (AHPGr). El Catastro del Marqués de la Ensenada en el Antiguo Reino de Granada. Instrumentos de descripción 16, Junta de Andalucía. 
Motril en el siglo XVIII cuenta con un total de 1929 vecinos y 59 eclesiásticos, lo que la sitúa en torno a los 9.000 habitantes, un cifra importante si la comparamos con las localidades vecinas, que tendrían una población notablemente inferior, como el caso de Almuñécar con 642 vecinos, Salobreña con 319 y Gualchos y Jolúcar con 265 o Vélez de Benaudalla con $271^{38}$. Por tanto, nos situamos en la localidad entre Vélez-Málaga y Almería más poblada del litoral.

La actividad económica predominante durante la época moderna es la agraria, aunque comienza a haber cada vez más menciones sobre el comercio marítimo, sobre todo en la solicitud de protección militar, lo que tuvo incidencia directa en las hospederías. Así, Antonio Gómez Becerra y Adela Fábregas García detectan en el siglo XVIII una crisis del comercio de seda y azúcar, que progresivamente irá supliéndose con el de algodón con destino a Barcelona y otras plazas del litoral peninsular y europeo, aunque encontremos numerosas embarcaciones dispuestas a cargar azúcar. Las comunicaciones de Motril condicionaron el desarrollo económico. Tan solo hay dos caminos de ruedas entre Motril y Calahonda y Motril y Vélez de Benaudalla. Lo demás son caminos de herradura entre múltiples veredas ${ }^{39}$.

En este contexto, la pregunta vigésimo nona del Interrogatorio General del Catastro de Ensenada en Motril nos informa de la existencia de cuatro mesones: el mesón de la Puerta de Castil de Ferro (en la actualidad Castell de Ferro), el mesón del Postiguillo que llaman Postiguillo de Beas, el mesón de la Puerta de Granada y el hostal o mesón Motril, denominado también El Nuevo.

Partiendo de esta información, vamos a aportar algunos datos que nos proporciona el Catastro sobre los citados mesones, sus propietarios y mesoneros. Ampliaremos estas informaciones con otros documentos. Pero antes, hay que señalar que para el caso de Motril hemos encontrado algunas dificultades. En primer lugar, el libro de lo Real no nos permite estudiar las estructuras, ya que solo registra las medidas del solar. Sorprende esta fórmula de describir las casas y mesones, pues la mayor parte de la documentación catastral de los lugares del reino de Granada, nos informa de las plantas, los cuartos, las caballerizas o el patio. Un hecho que también tiene su reflejo en la regulación de la utilidad, que en este caso no se realiza por el tamaño de la edificación, sino por la cuantía de su arrendamiento. Por contra, en Motril nos revelan quiénes vivían en las casas o mesones.

38. A. Domínguez Ortiz; C. Camarero Bullón y J. Campos (1991), 510-511.

39. A. Gómez Becerra y A. Fábregas García (1996), 101-108. 
Otra de las dificultades ha sido localizar en los libros de los Cabezas de Casa a los propietarios de estos mesones para estudiar su capital sujeto a gravamen fiscal en la ciudad. Hemos podido documentar a tres de ellos, pero no hemos encontrado información de los herederos de don Juan Alejo, propietarios del mesón del Postiguillo de Beas, que no aparecen en el Catastro. Las Respuestas Generales nos dicen que dicho mesón del Postiguillo de Beas estaba administrado por el propio don Juan Alejo, que tenía una persona sirviente para que lo cuidara. Le regulan de producible e industrial 800 reales de vellón, por ser ninguno el tráfico de arrieros que en él entra ${ }^{40}$.

Lo mismo ocurre con los mesoneros. En el caso de algunos, incluso hemos podido saber en qué mesón servían, pero en el caso de otros tan solo contamos con que el vecindario los registra como tales.

\subsection{Normativa legal y otras disposiciones}

La política centralizadora de los Borbones también tuvo su influencia en las ventas, mesones y posadas, que pasaron a depender del superintendente de caminos y a ordenar mejoras. No obstante en la Edad Moderna, la preocupación de la Corona estuvo más en controlar los gravámenes a los víveres que en ellas se vendían para controlar el cobro de impuestos, o las políticas de precio justo ${ }^{41}$.

Del mismo modo, la política arancelaria tuvo su impacto en la normativa local, quedando reflejada en las ordenanzas y otra documentación concejil. A partir del trabajo del profesor de historia del derecho de la Universidad Complutense de Madrid, Pedro Andrés Porras Arboledas ${ }^{42}$, podemos acercarnos a algunas normativas que se refieren al servicio de hospederías en la Edad Moderna, y que nos orientan sobre las prácticas de buen gobierno en estos espacios, la seguridad o los problemas a los que había que dar respuesta.

Ya en 1638, el licenciado Manuel Corbera y Abelló, consultor de la Inquisición y alcalde mayor de Motril, dictó un conjunto de 21 normas en un auto de buen gobierno entre las que se encontraban la de no acoger en los mesones

40. AGS, CE, RG Motril, Libro 293, fol. 205r-207r. Respecto a don Juan Alejo, solo he podido localizar en los vecindarios eclesiástico y secular a una persona que responda a este nombre, don Juan Alejo Presbítero, pero entre sus propiedades no se encuentra este mesón.

41. Véase M. Á. Pérez SAmper (2006), 391-424. En este trabajo hace un recorrido por las leyes y tratados de la época moderna referida a las ventas, posadas y mesones, destacando la preocupación existente por su mejora y control.

42. P. A. Porras Arboledas (2005), 151-177. 
a rufianes, mujeres de mal vivir o ladrones y la de guardar los aranceles, tener limpios los pesebres, no meter en caballeriza gallinas ni puercos y tener buena paja y cebada. Esta prohibición se ampliaba a personas sospechosas de estar amancebadas o ser alcahuetas. Al mismo tiempo este auto prohibía a los mesoneros vender comida en sus casas, una medida que coincidía con otras disposiciones adoptadas para todos los territorios de la Corona.

En 1754 se dictó otro auto por el gobernador político y militar y superintendente de rentas de Motril, el teniente coronel Pablo Florencia con 13 disposiciones, en las que se introducía la obligación de identificar a los huéspedes de los mesones. Explica Porras Arboledas que el control e identificación de los caminantes que transitaban por Motril era notable, aunque pesara a los mesoneros que debían tener preparado cada noche el informe con las personas que se hospedaban, detallando a qué se dedicaban y cuál era su destino final. Además, incide el profesor Porras, estaban obligados por ley a denunciar a personas sospechosas de haber cometido delitos de contrabando, deserción o robo.

En lo que respecta a materia sanitaria, en la Edad Moderna las autoridades de Motril se preocupan por que los mesoneros mantuviesen en buen estado de salubridad los cuartos, camas y pesebres con el fin de evitar enfermedades. Pedro Andrés Porras concluye afirmando que casi todos los estamentos sociales de Motril estaban en el punto de mira de la justicia. En el caso de los mesones, los mesoneros estaban en el punto de mira por defraudadores, por lo que había una especial ofuscación en que cumpliesen con los aranceles y los colocasen en lugar visible.

En síntesis, el Concejo de Motril centró su interés en la seguridad, la salubridad y el decoro. También en el oficio de mesonero para controlar precios o incluso el apoyo a estafadores o piratas, pero no hemos encontrado que prestaran atención a la mejora del edificio en sí.

\subsection{El mesón de Castell de Ferro}

El mesón de Castell de Ferro ${ }^{43}$ se ubicó en la puerta de Castell de Ferro de la ciudad de Motril (actual entrada a la calle Zapateros). Lindaba con

43. AHPGr, CE, Respuestas particulares del vecindario eclesiástico y secular (RP), Motril, Libro 124, fols. 156r-157r. Aunque en el texto evitaremos el término Respuestas Particulares y utilizaremos su terminología apropiada (libro de los Cabezas de Casa y libro de lo Real), para facilitar su localización en el archivo seguiremos la denominación que actualmente tienen y que en su momento se le dio en el Archivo de la Real Chancillería de Granada en cuanto a su clasificación por series documentales que fijó la 
la rambla y con los cubos de dicha puerta por la parte de arriba, y por la parte de abajo con la casa de Blanqueo. Tenía 20 varas de frente por 24 de fondo, y el catastro no aporta más información sobre su morfología, aunque podemos suponer que esta construcción respondería a la estructura general de los mesones del reino, con dos alturas, cuadras o corrales en los cuartos bajos, patio, y habitaciones en los altos.

El mesón era propiedad de la Compañía de Jesús de la ciudad de Motril y le regulan 700 reales de vellón ${ }^{44}$. Dicha institución religiosa contaba en Motril con tres casas más, todas ellas en la plazuela de la puerta de Castell. Una de 18 varas de frente por 6 de fondo en la que vivía Francisco Gerónimo en régimen de arrendamiento por 180 reales de vellón al año. Otra de 4 varas de frente por 15 de fondo habitada por José Pérez, de oficio jornalero, que pagaba de renta 120 reales de vellón al año. Y por último, la casa en la que vivía Francisco Martín Pecharos, de 4 varas de frente por 23 de fondo, por la que pagaba una renta de 180 reales de vellón.

La Compañía de Jesús también contaba en Motril con cinco plantíos de cañas a los que se les regulaban 9.556 reales de vellón, con un pago de tierra de tercera calidad que no labraba, siendo para semillas y con dos pagos de tierras de secano que sumaban un producto de 52 reales de vellón y 11 maravedís. Además, contaba con 230 ovejas de vientre, 100 carneros, 170 corderos, 6 cabezas de ganado asnar y 2 cabezas de ganado mular. Por todo el ganado se le regularon 2.616 reales de vellón. En total, tenía un producto de 12.436 reales de vellón y 11 maravedís.

En las Respuestas Generales aparece como mesonero del mesón de la Puerta de Castell, Nicolás Luis Sapio, cuya información podemos ampliar en el vecindario ${ }^{45}$. Era cabeza de una casa con seis miembros, Nicolás Luis de 30 años vivía con su esposa Ana María Cavañas de 19 años y sus hijos menores Carmen Manuel y Bárbara María. Contaba con dos criados, también menores de edad, Josefa Márquez y Agustín Ruiz, siendo el único mesonero de las tierras de Motril y de los partidos del Valle de Lecrín, Órgiva, Torvizcón y las Alpujarras que tiene en su hogar criados. No se le registra ninguna propiedad en Motril, ni

Superintendencia General de Rentas: Respuestas particulares del vecindario eclesiástico y secular. URL: http://www.juntadeandalucia.es/cultura/archivos_html/sites/default/ contenidos/archivos/ahpgranada/documentos/ISAD_G_Catastro_Ensenada.pdf

44. AGS, CE, RG Motril, Libro 293, fol. 205r-207r.

45. AHPGr, CE, RP Motril, Libro 1425, fol. 32r. 
ninguna actividad más que la industrial de mesonero, que le produce 1.100 reales de vellón ${ }^{46}$.

\subsection{El hostal o mesón Nuevo}

El hostal o mesón Nuevo de Motril $^{47}$ se situaba en la plaza de la Victoria. Llama la atención que el Catastro utilice el nombre de "hostal o mesón", pues para todo el reino, como hemos analizado en otros trabajos el término utilizado es mesón, venta, posada, hostería, y ventorrillo. En este caso, la propia documentación lo asimila a mesón y en el libro de lo Real no aparece el término hostal, pero sí nos gustaría subrayar que nos encontramos ante un mesón con una planta muy amplia (29 varas de frente y 33 varas de fondo). Quizá debido a su tamaño se comience a hablar de hostal, pero esto es algo que debe estudiarse en profundidad.

Propiedad de Francisco Cava mayor, lindaba con la casas de Simón Sánchez por arriba, y lo tenía arrendado por 1.300 reales de vellón siendo de su cuenta las obras y reparos. No tenía más propiedades en Motril, y además del mesón, se le regulaban 3 reales de vellón diarios por su jornal que al año hacían 540 reales de vellón.

El mesón Nuevo estaba arrendado al arriero José Cava mayor ${ }^{48}$ que tenía en Motril tres casas. Una casa arruinada de 5 varas de frente por 9 de fondo, otra en la rambla del Manjón con bodegas y lagar de 12 varas de frente por 12 de fondo, por la que se le regulaban 120 reales de vellón, y la casa en la que vivía de 20 varas de frente por 14 de fondo. Situada en la puerta de Granada, se le regulaban 260 reales de vellón. A estas propiedades inmobiliarias se le sumaban dos piezas de tierra, una de secano con una utilidad de 36 reales de vellón y 6 maravedís y otra de viña con una utilidad de 1.050 reales de vellón; frutales con una utilidad de 240 reales de vellón y 7 cabezas de ganado mular, 7 asnar y 1 caballo por los que le regulaban 350 reales de vellón. En la parte de industrial se le regulaba el ejercicio de arriero por una cantidad de 3.300 reales de vellón al año y el mesón que tiene arrendado de su cuenta con 1.100 reales de vellón. Sumaba de producto 6.106 reales de vellón y seis maravedís.

46. AHPGr, CE, RP Motril, Libro 1427, fol. 264r.

47. AHPGr, CE, RP Motril, Libro 1425, fol. 483r.

48. AHPGr, CE, RP Motril, Libro 1425, fols. 415r-416r. 
Era de la cuenta de José Cava mayor pagar al mesonero Pedro Jáuregui $^{49}$, que componía su hogar junto a su mujer, Francisca Olivencia de 31 años y su hija menor llamada María. No hemos encontrado que tenga propiedades en Motril, ni lo que se le regulaba por el oficio.

\subsection{El mesón de la Puerta de Granada}

La casa mesón de la Puerta de Granada ${ }^{50}$ es de la que más noticias tenemos. Comenzaremos hablando de los datos que nos proporciona el Catastro para ampliar esta información con documentación complementaria obtenida de documentos del Archivo Histórico de la Nobleza, que nos ayudarán a comprender su arrendamiento, su problemática o su estructura.

Esta hospedería estaba situada en la calle Puerta de Granada. Tenía 19 varas de frente y 23 de fondo. Propiedad del marqués de Algarinejo, lo vivía y estaba a su cargo Pedro Sazo Javichon, pagando de renta 800 reales de vellón.

La casa de Algarinejo pasó en la Edad Moderna de ser una oligarquía local a una de las casas nobiliarias más importantes del reino de Granada gracias a su política matrimonial y de compras. Enrique Soria Mesa lo sintetiza extraordinariamente de la siguiente forma:

La casa de Algarinejo se constituye en una de las más poderosas e importantes familias de la nobleza andaluza a finales del siglo XVIII. Para ello ha efectuado un rápido y progresivo ascenso social desde un estatus inicial bastante inferior. La bastardía originaria no representó para la familia ningún impedimento debido a la decidida protección del linaje (representado por doña Francisca de Córdoba). La posesión de un destacado nivel de fortuna, vinculado desde un primer momento, permitió a los sucesivos titulares de la Casa ostentar una posición social muy encumbrada, lo que traería como resultado, entre otros, unos casamientos excepcionales, pues casi todas las esposas fueron herederas de sus linajes, aportando mayorazgos, señoríos e incluso títulos de Castilla ${ }^{51}$.

A principios del siglo XVII el señor de Algarinejo, don Mateo de Lisón y Viedma ya es veinticuatro de la ciudad de Granada y procurador en las Cortes de 1621. Fruto de esta política matrimonial llega a Motril, donde contrae matrimonio con doña María de Contreras, una rica heredera, hija

49. AHPGr, CE, RP Motril, Libro 1425, fol. 22.

50. AHPGr, CE, RP Motril, Libro 1427, fols. 198r-209v.

51. E. Soria Mesa (1992), 334. 
única, con la que crea un mayorazgo vinculado al oficio de veinticuatro de Granada que consolida el patrimonio familiar y que recaerá en su hija, doña Mariana de Lisón y Contreras ${ }^{52}$.

En 1699 don Juan Fernández de Córdoba y Lisón obtiene el título de marqués de Algarinejo comprándolo a la Iglesia, pero la grandeza de España no pudieron conseguirla, a pesar de sus intentos ${ }^{53}$. En el siglo XVIII la familia posee numerosos mayorazgos repartidos por toda Andalucía, gracias a las políticas matrimoniales ${ }^{54}$.

En Motril, las averiguaciones catastrales de 1752 nos informan de que además de contar con el mesón, la casa de Algarinejo tenía diez casas arrendadas por las que ganaba 2.086 reales de vellón. La casa principal estaba situada en la rambla del Manjón. Lindaba por arriba con doña Theresa Sodines y por abajo con don Gonzalo Pacheco de Padilla; estaba arrendada por 800 reales de vellón al año al coronel de caballería don Francisco Maza, coronel de caballería y al soldado Manuel. Además tenía una casa en la Plazuela del Correo viejo arrendada a Manuel Garrido por 72 reales de vellón; la casa principal; una casa en la calle que va a San Francisco (9x15) que la vive Antonio de la Torre por la que paga una renta de 160 reales de vellón; una casa-tienda en la placeta Castell de Ferro $(4 \times 6)$, que la vive José M. zapatero y paga de renta 120 reales de vellón; una casa en la calle Muralla (10x19) en la que vive María Sánchez viuda y paga de renta 192 reales de vellón; una casa en la placeta de Pineda (9x12) que la tiene arrendada Juan Fernández jornalero por 144 reales de vellón; una casa-horno también en la placeta de Pineda $(18 \times 5)$ que estaba vacía y se le regulaba que podría ganar hasta 240 reales de vellón; una casa en la placeta del Marjalillo $(11 \times 6)$ en la que viven Antonio Rodrigo Thomas de Ruedas, Francisco Álvarez jornalero y Lorena Álvarez viuda, y pagan de renta 110 reales de vellón; otra casa en dicha plazuela $(4 \times 15)$ arrendada por Juan Marmor por 110 reales de vellón; otra más en la plazuela (10x13) que la tiene Francisco Guerrero jornalero y Ángela Montoro, viuda pobre y que pagan de renta 120 reales de vellón.

Además, el marqués de Algarinejo poseía numerosas tierras en Motril, con un capital fiscal importante que le situaba entre los propietarios más importantes de la ciudad. Entre sus propiedades, el Catastro registra doce piezas de tierras de calidad de cañas y hortalizas puestas en arrendamiento

52. Ibidem, 320-321

53. Ibidem, 331.

54. R. Molina Recio (2011), 57-112. 
que sumaban 168 marjales y producían 4.178 reales de vellón. En ellas había una casa huerta de 14 varas de frente por 4 de fondo y una casa de campo de 13 varas de frente por 5 de fondo. También tenía ocho piezas de tierra de segunda calidad puestas en arrendamiento, que suman 216 marjales, produciendo 1.803 reales de vellón; y 40 piezas de tierra de tercera calidad puestas en arrendamiento que suman 52 marjales, lo que le produce 1.086 reales de vellón.

Por otro lado, contaba con dos piezas de tierra de vega "incultas por desidia" que sumaban 32 marjales, y otras dos piezas de tierra "incultas por naturaleza" que sumaban 57 marjales. Pero el marqués de Algarinejo no sería el propietario con más marjales de tierra, sino que le superan el conde de Bornos, vecino de Madrid con 3.050 marjales, el marqués de Valera con 2.036 marjales y el Convento de la Victoria con 1.776 marjales, lo que nos confirma que la tierra se concentraría en pocas manos ${ }^{55}$.

El marqués de Algarinejo pagaba memorias en la ciudad de Motril al convento, a los pobres de la cárcel, a la Real Población o a la limpia de la acequia, y también poseía censos a su favor. Hay que destacar que tiene un oficio enajenado de la corona, el de regidor perpetuo de la ciudad de Motril, que en el momento de realizar el Catastro no está en uso por cuya razón no le regulan utilidad. Esto demuestra la importancia de este marqués en la ciudad, y la política de la que hemos hablado.

En total, el Catastro le regula al marqués de Algarinejo en Motril un producto de 32.428 reales de vellón, lo que contribuía a las rentas que le calcula Soria Mesa para finales del siglo XVIII, ascendiendo a unos 70.000 ducados $^{56}$, y le sitúa muy cerca de las rentas de la alta aristocracia, con numerosos señoríos que suman grandes extensiones de tierra en Córdoba, Écija, Loja, Rute, Campo de Gibraltar, Motril o Salamanca.

El mesonero que sirve esta hospedería es Pedro Sazo Javichón ${ }^{57}$ de 56 años, que vive con María Teresa Decara de 38 años, y sus hijos menores Antonio, José, Pedro y Rosa. Se le considera de utilidad 800 reales de vellón, no registrándole ninguna propiedad ${ }^{58}$.

A partir de las cuentas de administración referentes a los bienes que los marqueses de Algarinejo poseen en Motril (Granada), desde 1705 a 1743,

56. E. Soria Mesa (1992), 332.

57. AHPGr, CE, RP Motril, Libro 1425, fol. 28r.

58. AHPGr, CE, RP Motril, Libro 1427, fol. 365 r. 
rendidas por diferentes administradores ${ }^{59}$, sabemos que el arrendamiento de los mesones cambiaba regularmente, que este mesón pagaba la renta en Granada y que los precios también cambian a lo largo de la centuria. En 1705 Juan del Río Bizo tiene arrendado el mesón por ocho años en precio de 650 reales de vellón. En 1726 el arrendatario es Francisco Martín y de 1729 a 1730 el arrendatario es José García Franco. En este año cambia de arrendatario a Francisco García Torres en precio por cada año de 900 reales de vellón y 30 cargas de estiércol en dos pagas, una en Navidad y otra en san Juan. En 1731 aparece como arrendataria Isabel García, viuda de Francisco García Torres, que continúa pagando los 900 reales de vellón hasta 1733 en el que se le rebajan a 840 reales de vellón, y 30 cargas de estiércol, precio que mantiene hasta 1743.

Varios autos ejecutivos nos informan de que el marqués de Algarinejo tuvo que reclamar las deudas del arrendamiento del mesón a Juan Martínez Abasto y Rosalía López Calderón su mujer ${ }^{60}$.

El continuo cambio de arrendatarios también creó problemas como se desprende de la cesión que tuvo que hacer en 1727 José García Franco con su esposa, Juliana de Arias de un haza de tierra en el Pago de los Tejares en Motril (Granada) para pagarle así al marqués de Algarinejo lo que le estaban debiendo del arrendamiento del mesón ${ }^{61}$.

Las escrituras de arrendamiento también nos aportan información sobre arrendatarios como Fernando Hernández y Manuel de Martos, del Mesón de la Puerta de Granada ${ }^{62}$.

La documentación referida ${ }^{63}$ también nos acerca a conocer la estructura edilicia a través del informe de una obra en el mesón en el año 1739 que nos proporciona algunas características de la edificación. La obra consistió en el arreglo de la postura de una viga madre que sujetaba un suelo cuadrado y del descargadero de él de 13,5 varas de largo, media vara de grueso y dos cuartas y media de tabla. Quitaron la postura que había y la pusieron nueva. También arreglaron el apuntalado de otra de las caballerizas de adentro que se estaba cayendo, y empedraron todo el frente de dicho mesón, desde el descargadero a la mitad de la calle en virtud del mandato de la Justicia. El coste de dicha obra fue de 635 reales y 17 maravedís y fueron

59. Archivo Histórico de la Nobleza (AHN), LUQUE, C.187, D.1-110.

60. AHN, LUQUE, C.451, D.109-115.

61. AHN, LUQUE, C.676, D.13.

62. AHN, LUQUE, C.566, D.58.

63. AHN, LUQUE, C.187, D.1-110. 
ejecutados con la intervención y asilo de Mateo Compán. La referida viga madre nueva costó 300 reales de vellón, a lo que se le sumaron 14 más por labrarla. Los apuntalados para sacar la vieja, poner la nueva, quitar las columnas sobre la que estaba, volverlas a poner, el yeso, las cuñas, sogas, etc. tuvo un coste de 230 reales de vellón; el porte para traer la nueva al mesón fue 35 reales y 17 maravedís; por el cuarto 12 reales de vellón; y el empedrado de la calle y el reempedrado del descargadero tuvo un coste entre piedras y mano de obra de 45 reales de vellón.

El 5 de octubre de 1740 se tasó el mesón de la Puerta de Granada, lo que nos aporta más noticias sobre el mesón. El solar ocupaba 558 varas cuadradas y la tasación ascendió hasta 22.334 reales de vellón por todo el mesón. Al año ganaba 850 reales de vellón y cada mes 70, lo que sumaría un valor de renta de 14.180 reales de vellón y 16 maravedís. En dicha ficha nos dicen las personas que hicieron la tasación y el coste de la misma, que fue de 52 reales y 8 maravedís dividido en 15 reales a Ana Palomares y otros 15 a Mateo Compán; 4 reales al ministro; 16 reales y 8 maravedís al oficio y 2 reales al juez.

\subsection{Apuntes sobre mesoneros y huéspedes en Motril}

Las noticias del servicio que prestaban los mesoneros generalmente nos llegan a través de la literatura de viajes. Como ya hemos dicho, la normativa estatal y local veló por la seguridad de los viajeros, pues en la época moderna las personas que ostentaban el oficio de mesonero, posadero o ventero tenían fama de personas indignas y ladronas, a las que se les sumaba la del abandono del servicio. José María Sánchez Diana incluso habla de que el oficio de ventero quedó como sinónimo de pillo y pícaro, en connivencia con la familia para robar al viajero ${ }^{64}$.

La documentación catastral no aporta datos referentes a la vida en la hospedería o los bienes muebles, objetos, enseres, ajuares, textiles...que la componían. Tampoco nos proporciona información para poder estudiar estos espacios de socialización, en el que se desarrollaban hábitos o tradiciones, sino que se limita a registrar a la persona que ejerce el oficio, la industria que se le regula, y los miembros de la unidad familiar. A partir de estos escuetos pero también interesantes datos, a lo largo del texto hemos ido señalando los mesoneros, pero encontramos uno más en el vecindario de Motril, Salvador Ximénez de 50 años, que vivía junto a su mujer de 40

64. J. M. SÁnchez Diana (1973), 5-57.

(C) Baetica. Estudios Historia Moderna y Contemporánea, 39, 2019, 251-283.

Facultad de Filosofía y Letras, Universidad de Málaga. Departamento de Historia Moderna y Contemporánea 
años y sus hijos menores Francisco, Ana y Diego ${ }^{65}$, y no podemos saber en qué hospedería prestaba servicio.

Además de la literatura de viajes, la normativa local y el Catastro de Ensenada, las actas capitulares del Concejo de Motril, cuyo estudio y catalogación en el siglo XVII ha sido el objeto de investigación de la tesis doctoral de Jesús Rodríguez ${ }^{66}$, nos aportan información muy útil para conocer y comprender la evolución política y socioeconómica de Motril y por ende, nos proporcionan algunas noticias de los mesoneros en la Edad Moderna.

Por ejemplo, sabemos que el Concejo celebró durante más de una década sus reuniones en el mesón de la Puerta de Granada, pues las casas del cabildo habían sufrido en 1620 una explosión por intentar abrir un barril de pólvora para repartirla a la gente ante un inminente ataque turco ${ }^{67}$. Del mesón del Postiguillo de Beas, tenemos noticias de que estaba situado junto al corral de comedias que en 1616 se vendió a Pedro García de Lobato y algunos años más tarde a Baltasar de Peralta que lo remodeló en 1635. Esta información ha quedado registrada gracias a la licencia que dio el Concejo para subir a ocho maravedís el precio de la entrada y el asiento con el fin de poder pagar los gastos que había ocasionado la construcción del graderío y la instalación de bancos en el edificio ${ }^{68}$.

Por tanto, además de las políticas de buen gobierno que hemos señalado en un apartado previo, el Concejo se preocupó de tres aspectos fundamentales: los actos delictivos, los acuartelamientos y el alojamiento de personalidades.

De los actos delictivos, las actas capitulares nos informan de la connivencia que tuvieron los mesoneros de Motril con los corsarios y arrieros para sacar más productos de lo concertado fuera de la ciudad, evitando el recuento del alcalde mayor. El Concejo determinó establecer una sanción de 3.000 maravedís, tanto para los infractores como para los mesoneros que participaran encubriendo el delito ${ }^{69}$. También tenemos algunas noticias de la vida en el mesón relativas a la venta y el almacenaje de víveres o paja. En una de las actas hay una petición al Concejo de Juan Cortés y de otros mesoneros para que no los condenaran por haber encerrado paja antes de

65. AHPGr, CE, RP Motril, Libro 1425, fol. 8r.

66. J. Rodríguez Gálvez (2015).

67. Ibidem, 153.

68. Ibidem, 217.

69. Íbidem, 182. 
san Juan. Alegaban que no se les había notificado que estaba prohibido. Asimismo, Juan Cortés solicitó que solo le impusieran una sanción de 100 maravedíes por no tener cédula firmada de la justicia cada mes. El Concejo acordó que solicitara justicia ante el alcalde mayor ${ }^{70}$.

Los acuartelamientos para el reclutamiento en los mesones fueron algo muy común en Motril. El 16 de marzo de 1639 llegó al Concejo una notificación de una patente, instrucción y real cédula presentada por el capitán don Cristóbal Zorrilla de Villalobos para reclutar una compañía de 100 infantes en esta villa, acordando que se cumpliera todo lo que se ordenaba en dicha cédula y se situara su bandera en un principio en el mesón de la Puerta de Granada ${ }^{71}$. El 5 de noviembre de 1639 se acordó que los soldados que venían a socorrer a la villa de la piratería y los navíos que estaban en la playa se hospedaran en los mesones de la ciudad, y el 14 de noviembre de 1639 el Concejo libró 50 reales a cada mesonero que hospedó en sus mesones a los soldados de la compañía de Órgiva ${ }^{72}$. El 23 de abril de 1642, se notificó de la llegada de don José Casanova, capitán de infantería, con una patente real para realizar una leva de 100 soldados voluntarios. El Concejo acordó que se cumpliera con la leva, ubicando su bandera debajo de la reja de la cárcel y asignándole para su estancia los mesones y casas de posada ${ }^{73}$, y el 27 de abril el capitán don José Casanova pidió permiso para enarbolar su bandera en el mesón de Juan Cortés en vez de por debajo de la cárcel, acordándose que el capitán se alojara y enarbolara su bandera en ese mesón durante el tiempo que estuviera en la villa ${ }^{74}$.

Además de los permisos y notificaciones para el uso de mesones como acuartelamientos y el alojamiento de soldados, el Concejo también tuvo que pagar algunos de sus gastos como se desprende de la petición al Concejo que realizó don Juan Ruiz Cabello el 14 de octubre de 1642 para que se pagaran los gastos de alojamiento que tuvieron él y don Juan Belluga en el lugar de Pataura durante la elección de sus oficiales. El Concejo libró los 100 reales que se adeudaban a Leonor de Portocarrero, viuda de Pedro Martín, mesonero de ese lugar ${ }^{75}$.

70. Ibidem, 1280 .

71. Ibidem, 872 .

72. Ibidem, 934

73. Ibidem, 1144.

74. Ibidem, 1146.

75. Ibidem, 1190. 
El Concejo de Motril también se ocuparía de sufragar los gastos de algunos huéspedes. Tenemos datos del pago de 421 reales para sufragar el gasto del mesonero Melchor por hospedar al canónigo Antonio de Moya, que se había trasladado a la ciudad para conjurar la plaga de langosta ${ }^{76}$.

\section{CONCLUSIONES}

A la vista del minucioso y pormenorizado análisis realizado sobre las hospederías en el litoral del reino de Granada, son varias las conclusiones generales que podemos establecer.

Lo primero es destacar el escaso peso de las hospederías en el litoral, siendo un 20,4\% del total del Reino, y concentrado en los focos comerciales entre los que destaca Málaga con 21 servicios de hospedaje. En segundo lugar, hemos detectado que su número disminuye conforme caminamos hacia oriente, registrando en el litoral de la actual provincia almeriense, cuatro en la ciudad de Almería y una en Vera, un porcentaje muy bajo si lo comparamos con la parte más occidental del litoral donde encontramos Estepona con cinco o Marbella con dos.

Comprobar la densidad de espacios de hospedajes en el litoral del reino de Granada a través de su localización en un mapa nos permite reafirmar, una vez más, la escasa importancia que tuvieron las vías de comunicación terrestres en el litoral. A excepción de algunos tramos donde la carretera sería de herradura o incluso de ruedas como el tramo entre Málaga y Vélez-Málaga ${ }^{77}$, en el resto encontramos veredas en las que con dificultad podrían caminar los animales utilizados para el transporte. Esta problemática se trasladará a las hospederías, pues en todo el camino del litoral no encontramos ninguna venta, a excepción de los dos ventorrillos a la salida de Málaga. No tendría sentido disponer ventas en caminos que no eran transitados, y las personas que se dedicaban al comercio de cabotaje podrían hospedarse en los mesones de las villas y ciudades costeras. Aún queda mucho por hacer en la indagación de estas vías de comunicación terrestres y marinas, que entendemos que en este trabajo solo podíamos esbozar.

A través de las hospederías también podemos identificar los polos comerciales del sur peninsular y el desarrollo de los caminos. No solo nos referimos a los de Málaga y Granada, sino a numerosos caminos en los

76. Ibidem, 985 .

77. A. Mayorga González (2015), 343-369; J. J. Avellaneda (2014), 67-71. 
que la arriería de corta distancia sería muy importante entre localidades como Marbella y Ojén, Alhaurín y sus alrededores, o Motril y Granada.

En cuanto a su propiedad, los datos que se han ofrecido nos indican que estaban en manos de los grupos sociales más poderosos (dones, clero y nobleza titulada). En el caso de Motril, los propietarios de mesones que hemos estudiado poseen un importante capital en la ciudad, destacando al marqués de Algarinejo, que como hemos visto contaba con numerosas viviendas y tierras.

La información que hemos seleccionado respecto a las personas que explotan estas infraestructuras vuelve a dibujarnos un perfil de familias generalmente sin propiedades (excepcionalmente con pocas propiedades que les generaba un escaso producto), que se trasladaban al mesón en el que todos trabajarían, aunque encontramos determinados datos significantes como Nicolás Luis Sapio, que sirve en el mesón de la Puerta de Castell de Ferro y que cuenta con dos criados menores de edad. No obstante, las fuentes estudiadas guardan mucho silencio sobre la vida de estos mesoneros, que generalmente tendrían arrendados los mesones por un periodo determinado de tiempo, como se desprende de la documentación consultada.

Las estructuras edilicias de los mesones de Motril han sido imposibles de establecer con las noticias que nos da el Catastro, aunque sí podemos comprobar que los mesones de Motril eran más amplios que la media de las viviendas, teniendo de solar el mesón Nuevo 660 varas cuadradas, el mesón de la Puerta de Granada 437 varas cuadradas y el mesón de Castell de Ferro 460 varas cuadradas. Todos ellos son sensiblemente más amplios que las viviendas que hemos estudiado en Motril, con excepciones como la casa principal del marqués de Algarinejo, que con 25 varas de frente y 35 de fondo sumaban un solar de 875 varas cuadradas. Tendrían al menos dos alturas, aunque como ya hemos dicho, aunque el Catastro para Motril obvia esta información. Del mesón de la Puerta de Granada sí sabemos que como mínimo tendría dos alturas gracias a la información administrativa del marquesado de Algarinejo. Por tanto, nos encontramos ante unas construcciones amplias.

Si las comparamos con las hospederías de los Partidos del Valle de Lecrín, Órgiva y las Alpujarras, de los veintidós espacios de alojamiento de los que tenemos las medidas de su solar, tan solo superarían a los de Motril el mesón de Pinos del Valle ubicado en la calle real del Barrio Alto. Propiedad de los hermanos de Salazar tendría 32,5 varas de frente por 34,5 de fondo, con cuatro cuartos altos, tres bajos, tres cuadras y patio y la venta de Nigüelas que se encuentra en el Camino Real entre el Valle de 
Lecrín y las Alpujarras con 36 varas de frente y 18 de fondo, estructurada en dos plantas con patio, corral, pajar y caballerizas. El mesón de Órgiva tendría tamaño muy parecido a los de Motril con 26 varas de frente por 22 de fondo. Los restantes serían sensiblemente más pequeños, comprendidos entre las 12 varas cuadradas que tiene el solar de la venta de Padul, y las 360 varas cuadradas del mesón de Ugíjar.

Son muchas las dificultades que encontramos para estudiar una infraestructura viva como es un espacio de hospedaje, pues la fuente que hemos seleccionado nos aporta numerosos datos, pero su función principal no es responder a muchas de las cuestiones que nos hemos planteado. No obstante, a lo largo de estas páginas se intentan apuntar algunas cuestiones referentes a su explotación, a través de las noticias que encontramos en las actas capitulares del Concejo de Motril y la normativa que dictó dicho Concejo referente a los mesones en los siglo XVII y XVIII. Sobre Motril nos informa que los mesones servirían para alojar a las tropas que luchaban los ataques por mar, incluso colgando sus banderas en dichos mesones. Además, también acogerían a personalidades del clero. En cuanto a la normativa, se advierte el interés del Concejo por regular las prácticas para el buen funcionamiento del servicio, centrando su preocupación en los aranceles, las personas que acogen y el control de los mesoneros, todas ellas en concordancia con las que se venían regulando desde la Corona.

Tenemos especial interés en remarcar, que en el marco del siglo XVIII, hay que concebir estos espacios en el contexto del comercio, el transporte y los caminos, pues así lo hace el propio Catastro. Pero, también hay que tener en cuenta su multifuncionalidad, ya que en ellos habita una familia, o como hemos dicho servirían como acuartelamientos en determinados momentos, lo que nos plantea la necesidad de profundizar en el papel que cumplen estos servicios de hospedaje en cada contexto, en lo urbano o el camino, en las ciudades o las villas, en los territorios de tránsito y los que no. Más aún, si esto explica la regulación de su utilidad y del trabajo de las personas que los sirven.

En definitiva, son muchos los silencios y las cuestiones en las que no hemos podido profundizar y que es necesario señalar como futuras líneas de indagaciones. Nos referimos a un estudio del trabajo personal en los mesones, un trabajo que como ya hemos dicho reiteradamente lo harían todos los miembros de la familia, por lo que en él está oculto el trabajo personal femenino, una cuestión que debemos tener siempre en cuenta.

Consideramos que a lo largo de estas páginas hemos abierto más que cerrado líneas de indagación: la necesidad de hacer estudios territoriales 
donde se analicen estos espacios en relación a la economía local; ahondar en las características de los arrendamientos de los mesones; comparar las normativas locales que se interesaron en regular aspectos referentes a estos servicios; estudiar la vida en los mismos deteniéndose en el trabajo de mesoneros y sus familias, así como en la atención a huéspedes; o profundizar en su morfología, mobiliario, objetos, etc. En resumen, un tema apasionante con múltiples vértices de estudio.

\section{BIBLIOGRAFÍA}

Avellaneda, Juan José (2014), “La junta de los caminos. Málaga de ayer y de siempre", eDap. Documentos de Arquitectura y Patrimonio, 07, pp. 67-71.

Bacas BacAs, Francisco (2007), "Motril en el siglo XVIII", en J. M. Pérez Hens (coord.), Historia de Motril y la Costa Granadina, Motril, pp. 140-165.

Birriel Salcedo, Margarita María (1989), La tierra de Almuñécar en tiempo de Felipe II. Expulsión de moriscos y repoblación, Universidad, Granada.

Brotons Pazos, Juan (1995), Relación de las obras que se han executado en los caminos que desde la ciudad de Málaga se han abierto hasta las de Antequera y Vélez..., Ministerio de Obras Públicas, Málaga.

Burgos NúÑez, Antonio; Olmo García, Juan Carlos; SÁez Pérez, María Paz (octubre 2015), "El Camino de Vélez, pervivencia de una carretera de la España de la Ilustración", TST, 29, pp. 36-63.

Diago Hernando, Máximo y Ladero Quesada, Miguel Ángel (2009), “Caminos y ciudades en España de la Edad Media al siglo XVIII”, En la España Medieval, 32, pp. 347-382.

Gómez Becerra, Antonio y Fábregas García, Adela (1996), "La Costa de Granada. El territorio y la vida marítima. De la Prehistoria al Siglo de las Luces", El Puerto de Motril, Motril, pp. 31-109.

Jiménez Estrella, Antonio y Maroto Martos, Juan Carlos (junio 2004), "Estado, distancia y control social: Reflexiones en torno a una medición de caminos en la Granada de mediados del siglo XVI", Scripta Nova. Revista electrónica de Geografía y Ciencias Sociales de la Universidad de Barcelona, VIII, 166. URL: http://www.ub.edu/geocrit/sn/sn-166.htm

Jurado SÁnchez, José (1988), Los Caminos de Andalucía en la segunda mitad del siglo XVIII (1750-1808), Ayuntamiento, Córdoba.

JuRAdo SÁnchez, José (1992), “La red viaria malagueña en la segunda mitad del siglo XVIII", Estudios Regionales, 32, pp. 73-106.

Madrazo Madrazo, Santos (1984), El sistema de comunicaciones en España, 1750-1850, vol. 2, Turner, Madrid.

Mayorga GonzÁlez, Antonio (2015), "El camino de Málaga a Vélez", Isla de Arriarán, XLII-XLIII, pp.343-369. 
Las hospederías en el litoral del reino de Granada: los mesones de Motril... 283

Molina FAJARdo, María Aurora (2012), El espacio rural granadino tras la conquista castellana: urbanismo y arquitectura con funciones residenciales en el Valle de Lecrín en el siglo XVI. Tesis doctoral inédita, Universidad de Granada.

- (2020), "Por los caminos del siglo XVI. El hospedaje en la senda Granada-Motril a su paso por el Valle de Lecrín", Chronica Nova, en prensa.

Molina Recio, Raúl (2011), "El largo camino hacia el individualismo. El Palacio de los Condes de Luque en Granada en los inicios de la contemporaneidad", Historia y Genealogía, 1, pp. 57-112.

Pérez SAmper, María de los Ángeles (2006), "Ventas, mesones y posadas en la España Moderna", Estudios de Historia Moderna. Homenaje a la Doctora María Isabel Pérez de Colosía, Rodríguez, Universidad, Málaga, pp. 391-424.

Pezzi Cristóbal, Pilar (2003), Pasa y limón para los países del Norte. Economía y fiscalidad en Vélez-Málaga en el siglo XVIII, Universidad, Málaga.

Porras Arboledas, Pedro Andrés (2005), "La vida cotidiana en el Motril de la Edad Moderna a través de los Autos de Buen Gobierno", Cuadernos de Historia del Derecho, 12, pp. 151-177.

Rodríguez Gálvez, Jesús (2015), El Concejo de Motril a través de sus Actas Capitulares (Siglo XVII), Tesis inédita, Universidad, Granada. URL: http:// hdl.handle.net/10481/35224

SÁnchez Diana, José María (1973), "Viajes, viajeros y albergues en la España de los Austrias", Chronica Nova, 8, pp. 5-57.

Soria Mesa, Enrique (1992), "El señorío de Algarinejo (siglos XVI-XVIII)", Revista del Centro de Estudios Históricos de Granada y su reino, 6, pp. 319-334. 